Portland State University

PDXScholar

University Honors Theses

University Honors College

$11-16-2018$

\title{
Understanding Self-Constitution
}

Winston Meier

Portland State University

Follow this and additional works at: https://pdxscholar.library.pdx.edu/honorstheses

Let us know how access to this document benefits you.

\section{Recommended Citation}

Meier, Winston, "Understanding Self-Constitution" (2018). University Honors Theses. Paper 640.

https://doi.org/10.15760/honors.655

This Thesis is brought to you for free and open access. It has been accepted for inclusion in University Honors Theses by an authorized administrator of PDXScholar. Please contact us if we can make this document more accessible: pdxscholar@pdx.edu. 


\title{
Understanding Self-Constitution
}

\author{
by \\ Winston Meier
}

An undergraduate honors thesis submitted in partial fulfillment of the requirements for the degree of

Bachelor of Science

in

University Honors

and

Philosophy

Thesis Adviser

Dr. Angela Coventry 


\section{Introduction}

Contemporary views on narrativity argue that having a self-narrative is necessary for agency, unity and wellbeing (Schechtman 2013; Mackenzie 2009). Not without variation, these views equate narrativity to a type of autobiography, and present it as a more complex conscious experience than that of bare, first-personal subjectivity. However, critics have argued that selfhood cannot be confined to a narrative, and that narrativity is not the only means to rewarding, agentive living (Strawson 2004; Zahavi 2007). This paper examines whether narrative selfhood inhibits or empowers one's capacity for a good life, which is considered largely in terms of one's ability to act rationally and effectively. I argue that self-narratives are useful organizing structures for memories and ideas which are particularly vivid and laden with emotive and informational content. However, decoding these mental artifacts through focused reflection renders the narrative superfluous and obstructive. I argue against the notion that selfhood is solely constituted by a narrative, invoking Dan Zahavi's (2007) view of a primitive, first-person perspectival, "minimal self" that precedes one's autobiographical self. I reject the view that one is devoid of any working temporal schema if they do not inhabit a self-narrative, invoking Galen Strawson's (2004) notion of episodic selfhood. Considering these views, I posit that a simplified, localized self-experience is optimal for engendering agency and positive affect.

\section{Background on Narrativity}

Narrative theorists understand a self-narrative to be, most generally, a construct that organizes sensory information into some coherent order that, if made explicit, would resemble an autobiography or story (Schechtman, 2011). However, views regarding the composition, expression and function of the narrative, as well as the extent to which a narrative constitutes the 
self, vary considerably. Marya Schechtman has critiqued narrativity and advanced her own view called the 'Narrative Self-Constitution View' (NSCV). Schechtman understands narrative theories to fall rather neatly into three categories regarding their form, impact on lived experience, and the extent to which they are explicit or internally sensible ${ }^{1}$ (2007). These are the weak, medium and strong views. I will recount these views to give a comprehensive account of narrative theory and its nuances, before highlighting the more consistent and foundational aspects of narrativity which I will be critiquing.

The weaker view claims that any sequential ordering of events qualifies as a narrative, and that such an ordering can operate purely subconsciously but is necessary for one to function (Schechtman 2007). Catriona Mackenzie's account of narrativity would likely qualify as the weaker view. She defends narrativity by expanding the definition of self-narratives to include 'any sequential ordering of events,' such that one has the capacity to organize events into a temporal framework and act within that framework (2010). Mackenzie rejects the "story-telling" view of narrativity and the claim that those with self-narratives have a tendency to become distracted by the past or self-absorbed. She counters that narratives are themselves "implicit organizing structures," operating implicitly (as opposed to an internally audible narration) as they arrange sense perceptions in a coherent order (34). Without one, she claims that one remains lodged in the "stagnant present," absent any sense of time's passing or any filter for incoming sensory information (42).

Schechtman, I believe, is right in doubting whether this sort of organizing device qualifies as a narrative, though having some temporary schema and working sense filter is indeed

\footnotetext{
${ }^{1}$ By 'internally sensible' and explicit I mean something that is represented and comprehended mentally, such that, if prompted, they could think out a narrative segment and announce that narrative segment.
} 
necessary for survival and well-being. Briefly, if we can demonstrate that the 'coherent order' into which perceptions are arranged is not narrative in form (for instance, it is non-literary) or composition (for instance, it is impersonal), then we can discard the idea that there is some "implicit organizing device" called a narrative that is organizing these perceptions. We can assume, rather, that having a temporal extension is a basic component of intelligent, conscious creatures, and one need not identify as diachronic ${ }^{2}$ or narrative to inhabit that extension. I will expand on these distinctions in Section 5.

The stronger view can be recognized in such theorists as Daniel Dennett and Alasdair MacIntyre, though they both also differ in important ways. Both theorists present a self-narrative as something that is entirely explicit. Dennett (1992) developed a thought experiment to demonstrate that self-narratives provide (or represent phenomenally) the unification of otherwise disunified cognitive processes. In it he likens a narrative to the novel Moby Dick, and describes its generation as a conscious, internally audible process of narrating segments of one's lived experience. The self is the protagonist of this story, however it lacks any observable qualities of its own. ${ }^{3}$ Rather it is the locus around which a series of actions appear connected and unitary. MacIntyre also discusses the "unifying" feature of self-narratives, wherein episodes are connected in their being part of a series of goal-oriented activities. The narrative is the medium through which actions are directed towards ends, and it is the format provided for this sequence

\footnotetext{
${ }^{2}$ Diachronicity refers to something that persists across time. Applied to identity, it would require that the "me" I remember during my third birthday is the same "me" who is doing the remembering (Strawson, 2004).

${ }^{3}$ Dennett takes a Humean position calling the self an 'abstractum' and likening it to a center of gravity. In an unusual way the self, for Dennett, does depend on a narrative, or rather it is a by-product of a narrative, landing him in the strong-view category. However, the self does not exist as a thing unto itself, similarly the center of gravity does not exist without a balancing object. It's also analogous to rubber-band ball (the narrative segments being rubber bands). There is no center or core ball to a rubber band ball (like there is no self to a narrative), but it appears as though the bands (narrative segments) are heaped around something. They are, in reality, just heaped upon each other.
} 
of telic activity. Without ends, and without being situated in a series of actions directed towards ends, actions are unintelligible and cannot be ascribed meaning, value, or an ethical standard. One's history becomes a jumble of fragmented incidents with no coherence. Like Dennett, there is no pre-existing, substantial self in MacIntyre's view that unifies episodes of experience. Yet, differing from Dennett, the self becomes through the construction of a self-narrative. ${ }^{4}$ The episodes of one's life are unified insofar as each event contributes to the resolution of the narrative. A narrative provides the temporally extended structure in which one can imagine a future resolution.

Schechtman (2011) calls MacIntyre's the "hermeneutical view," given that actions are interpreted through a narrative. She observes that the narrative must be explicit for it to ascribe value to action, as one must be conscious of ends to which their action is directed, that thereby grants their action ethical status. MacIntyre (1981) indeed states that one cannot experience the present without referring to a mental image of some future telos ${ }^{5}(215-216)$. Despite the explicit and stable character of the narrative in MacIntyre's view, the literary format of the narrative seems less of an imperative than in Dennett's view. For instance, he uses the example of a cookbook to explain how each step of a recipe is only given meaning for their collective ends of the final meal. This, like Mackenzie's view, seems to stretch the definition of a narrative such that it overlaps with that of a more basic working temporal schema. However, he does also depict a narrative as a kind of quest and synomizes it at times with a story. Though I agree that one's life can take on this format, I will be arguing that one's lived experience is improved if the structure of their life more resembles (to themselves) a cookbook rather than a novel.

\footnotetext{
${ }^{4}$ Hume similarly argues that the perceptions which constitute our personal identity, which are in a constant state of flux, can attain unification by being endowed with a common purpose, by being directed towards ends (1.4.6.11). ${ }^{5}$ Discussed further in Section 4.
} 
Schechtman's (2007) Narrative Self-Constitution View (NSCV) comprises the middle range of narrativity theory. Like MacIntyre, she views the self as constructed through the process of generating a narrative. However, her narrative need not be nearly as explicit as MacIntyre or Dennett describe it to be, though it has more stringent constraints than those applied by Mackenzie. Schechtman's criteria for a narrative include that it must be capable of being made explicit on command. This means that if I ask for an explanation of your behavior, as in: 'Why did you move to California?,' you can answer by recalling a segment of your narrative: 'I met my fiance and her family is from California, plus I found a high-paying job in LA.' Schechtman also discusses what is called the "reality constraint," that a narrative must be consistent with what other people might observe as part of that person's experience. For example, I can not offer my history of how I came to be the Queen of England, for example (162-163).

Schechman's (2007) view is more subtle than MacIntyre's, in that she allows for quasi-spontaneous action, as in acting 'because one felt like it,' without any telos that lies at the end of a journey (163). She does not see that a narrative provides any unifying or moralizing function at all, as in an event is not afforded an ethical status through its being contextualized by a self-narrative $(161,177)$. To explain this further, I will recount the distinction she makes between a person's narrative and a self-narrative. The person's narrative is their measurable, objective history from which one infers legal and relational obligations, including anniversaries, due dates, deadlines etc. $(173,170)$.

She argues the "phenomenological self" is more segmented and ephemeral, but is still experienced as narrative in structure. It arises on the basis of cues for personal, emotive memories to which people have "empathic access." An example could be a 'short story' that is 
replayed to one's self when they hear the wedding song of their ex-wife $(171,174)$. This would be a memory that one connects diachronically to (they feel it was them who was there getting married). Schechtman (2001), drawing from Raymond Martin, explains that for us to sympathize with the agent (ourselves) of an episode, we feel feelings consistent with that of the agent when we revisit the event, and we have a similar objective or value-object as the agent in that episode. Both the values, and emotions of the agent resonate with us. This sympathy or resonance of the agent, consistent with a "centered" (or 'from the inside') experience of the episode, is requisite for empathic access and thereby narrative constitution $(103,106) .{ }^{6}$ The sentimentality of the memory enables the diachronicity, which in turn provides the structure for the narrative.

Memories which might have otherwise been objective units measuring the passage of time, then becomes chapters in one's autobiography.

Schechtman suggests that these narrative self-segments do not offer a reliable metric for making moral judgements. Such judgements would be more emotionally-motivated (for it is the emotional connection to a memory that substantiates the narrative). These segments are also too ephemeral and spontaneous. They are constructed reflexively whenever one's memories or fantasies happen to be cued, and they vanish just as easily when a situation changes. The strong view would not regard one's self-narrative segments as effectively different from their objective histories, but rather as frames removed from the more historical person-narrative (Schechtman, 2007). MacIntyre's (1981) self-narrative is comprehensive and inclusive, as in it spans the entirely of a numerical person's life. ${ }^{7}$ Here, actions are still contextualized by their position in an

\footnotetext{
${ }^{6}$ Explain further 'from the inside' in section 3.B, and 2.

7 The literature distinguishes between numerical persons, who can be a sanctioned and reidentified on the basis of consistent features like fingerprints or DNA, and selves or characters which are given to greater flux and are experienced subjectively (Mackenzie 2009).
} 
extended telic series of behavior, and receive an ethical standard determined by the ends to which they were directed. The strong view then presents a narrative which is more fixed and extended than Schechtman's NSCV, and therefore it has graver ethical implications.

In Schechtman's (2007) view, one's phenomenological experience of a narrative may also be more segmented (disunified), as one has the capacity for multiple intersecting narratives depending on what memories or projections are cued by present events. Narrative-construction, to Schechtman, appears in general to be more organic, automatic, subconscious and evolving than those of the strong view (174-178). There is no "quest" in which one becomes embedded, as there is no fixed theme to which narrative segments must subscribe (173). However, one still interprets their actions through the context of a narrative, or more specifically to her view, a present moment is "conditioned" by the experienced past and anticipated future (162). ${ }^{8}$ This remains the case even if the narrative is shorter and subject to change. Schechtman also uses the term "story" as synonymous with narrative, alluding to its literary format (155).

Across the range of narrative theories there are some fundamental consistencies. The theorists I've described argue that a narrative (regardless of how explicit, extended or complex it is) is useful for organizing perceptions, for explaining or contextualizing present experiences and for facilitating action that is intelligible, meaningful and effective. Each theorist also recognizes the self as largely diachronic, (in his critique, Strawson observes that diachronicity is a prerequisite for narrativity) (2004). ${ }^{9}$ Furthermore, each theorist I've discussed argues that having a self-narrative is beneficial, and that one needs to have such a narrative to live productively,

\footnotetext{
${ }^{8}$ This point is articulated similarly by J.D. Velleman (1991) in his essay "Well-Being and Time," though like MacIntyre, Velleman makes no distinction between the self-narrative and the more objective person narrative. ${ }_{9}^{9}$ Again, for Schechtman this applies to the person-narrative as well as for the duration of a self-narrative. It may not be relevant to Dennett's view, given that, for him, the self is an abstractum.
} 
happily and even functionally. This position is what Strawson refers to as the Ethical Narrativity Thesis (ENT). Each theorist I've discussed would agree that without a narrative, one would feel a type of disorientation and fragmentation that would inhibit agential activity.

The critique that I will develop in the following sections of this paper, posits self-narratives as useful, if intermediary self-states. I reject Mackenzie's view which pathologizes non-narrative selves. I doubt that without a narrative one is lost amidst chaos of unintelligible sense data, though I recognize the need for a working temporal schema that may or may not present as a personalized autobiography. I similarly reject the view that actions need an extended telos to be intelligible or important. To this point I will discuss the different ways actions can have "ends," including actions that are thought to be exclusively autotelic. I will argue that it is beneficial to have proximal goals which are themselves 'means' to effective action, and which are malleable to changing circumstances. These are preferable to having fixed ends to which all of one's efforts are directed, ends which can easily become impossible or undesirable to realize.

Though I find Schechtman's (2007) middle view most reasonable, I will argue against her position that present experiences are always "conditioned" by the anticipated future and experienced past. I agree that this conditioning is an effect of a self-narrative, but I argue it can restrict one's capacity to understand present circumstances and act effectively, rationally and in such a way that generates positive affect for oneself and others. It is possible and preferable, I will argue, that one develop the capacity to act more intuitively without reference to a self-narrative (even if that narrative is implicit and the reference is subconscious). Thereby, one utilizes their consolidated knowledge which they derive from decoding the contents of their 
narrative. To develop this criticism, I will describe the type of phenomena of which a narrative is composed, such that it is distinguished from a neutral temporal extension.

\section{Narratives as Constituted by Charged Events}

Criticisms raised against narrative views of the self are largely rooted in the observation that inhabiting an abstract temporal extension does not qualify as having a self-narrative. One can have a conceptual schema of the past and the future, without organizing the episodes inherent to that schema into a story. Zahavi (2007) has argued that having some sort of "time-consciousness" is a necessary feature of conscious awareness and is not exclusive to humans (191-192). Strawson (2004), who denies having any sort of self-narrative, admits to having a lived past and an anticipated future that is represented internally to him. Yet, he denies having any major interest in either, nor does he locate himself (as he is presently) in his past or future frames. ${ }^{10}$ Narratives have to refer to some sort of personalized or diachronic life-story to be non-trivial, something beyond the sort of temporal schema Strawson and Zahavi describe (Schectman 2013, 408-409). Such an extended temporality must resemble a work of literature rather than an instruction manual. ${ }^{11}$ What kind of mental artifacts, then, must populate one's temporal extension for it to be reshaped into a colorful, elaborate mosaic (such that one would be interested in it in the way that Strawson is not)?

In "Against Narrativity," Strawson (2004) argues that one who does not identity as diachronic and does not conceptualize their life as a narrative can sometimes harbor exceptional memories to which they connect diachronically. He states that such individuals "connect to

\footnotetext{
${ }^{10}$ I will elaborate on Strawson's alternative 'episodic selfhood' in Section 5.

${ }^{11}$ An instruction manual being having a linear, temporal order but one in which each line of information has a neutral relationship to the others. A manual is analogous to an episodic temporal extension because it is ancillary but disposable. It is not commodified or valued beyond its initial contribution as a precursor to action.
} 
charged events in their pasts in such a way that they feel like those events happened to them," them referring to their selves as they are presently (the self who is indulging the memory)(430-431). These events are those to which Schechtman (2001) describes one as having “empathic access," as I discussed in the preceding section (Strawson 2004, 431).

Strawson is describing a spectrum across which we relate to the first-person point of view or the third-person perspective of ourselves as agents, afforded to us by our memories of the past or our fantasies of the future. Certainly most individuals have images that could be placed at both ends of the spectrum. At the episodic end, there could be night of intoxication where one feels they were 'not acting like themselves,' or arbitrary memories of an adolescent phase (a fear of ghosts or an obsession with dinosaurs, for example) long since outgrown and less available to identification. ${ }^{12}$ At the diachronic end, there may be embarrassing memories that when revisited resonate with a person's present doubts and insecurities, and trigger live feelings of humiliation. Strawson also cites the thought of one's death as that to which most people connect diachronically and recognize as a fate awaiting them as they are now.

For Strawson (2004), the charged quality of our images or episodes enables our connecting diachronically to them, which is to say the resonate emotionally with us as we are in the present. Strawson argues that narrativity then requires the further "story-telling" and "form-finding" tendencies, where we ascribe a form to the assemblage of charged images that is consistent with a narrative story arch (441-442). We do this, in part, by editing out neutral events or episodes that lack empathic access. Thereby, our temporal ordering of personal, emotive

\footnotetext{
12 Strawson (2004) gives the example of Henry James feeling that one of his masterpieces was written by an entirely different person (429).
} 
memories and projections comes to resemble a novel, complete with rising and falling action, twists and turns, climaxes, resolutions and afterwards.

Another way one might articulate the difference between episodic and diachronic memories is that the former feel inherited, almost like a collection of mental artifacts that can be examined and forgotten without special relevance to one's present self or to other temporally distant episodes. The latter are specific points in a narrative from which one can draw an unmistakable, causal connection to their present episode, such that they feel there is one consistent self moving across time from episode to episode. Here, one could argue that an empathic memory that perhaps represents a cause to their present effect, is actually a marker of one and the same episode that they are currently concluding or playing out - thereby determining their self as diachronic within that episode. Surely different memories or potentialities can become "charged" or given personal emphasis (while others can slip into insignificance) based on changing circumstances.

I think it is reasonable and useful to assert that self-narratives are constructed exclusively from these charged events to which one relates empathically and sentimentally, that may or may not constitute bookends of a demarcatable episode (432). In contemporary psychology, an example of such charged events would be flashbulb memories (FBMs). FBMs are exceptionally vivid, formative of one's social identity, deeply constituted by emotional content (demonstrated heightened activity in the amygdala during stimulation of FBMs) and prone to inaccuracy (Hirst \& Phelps 2016).

Hume argued that ideas are energized by associated impressions, such that they become anchored, assented to and dictatorial of our actions (1.3.7.5). An idea becomes a belief not by 
virtue of its veridicality but by virtue of its vividity - how impactful its expression is to the perceiver. I will refer to such mental artifacts as beliefs, FBMs and other "charged events" - as fixations. I understand fixations generally to be particularly vivid, compact mental representations occupying the memory or imagination. The content (and often the form) of fixations remains stable relative to one's immediate sense perception. By compact, I mean that upon introspection one could potentially extract much information from these artifacts. In other words, they are significant and symbolize much about one's identity and history. The discrete representation of an FBM (and its associated beliefs) could bestow much emotive content to a person, as well as etiological insight. For example, a first-personal image of 9/11 could communicate much to someone about their role as a citizen, mortal, urban dweller, family member, etc.

One can think of a narrative cropping up spontaneously (as with Schechtman's view) or as more deliberate, constructive "exercise of agency" (2007; Mackenzie \& Poltera 2010). Narratives are clearly useful for the systematization for FBMs or other fixations, insofar as an agent constructs their own narrative. Fitting the memory of a terrorist attack into a larger story (especially one with a nationalistic and heroic tilt) could make it intelligible and tolerable as a painful artifact of the past. Despite this perhaps ancillary function, I will argue using the following analogy that a narrative-self state should be temporary.

Consider a crime scene at which the investigator takes dozens of photos. The photos contain vital information that is not yet intelligible, and they must be organized into some coherent pattern so that the information is more accessible. So they are arranged into (and the detective uses them to construct) a type of narrative - entryway, blood on the stairs, murder 
weapon, exitway, tire marks, abandoned escape vehicle, home of the suspect, etc. ${ }^{13}$ All of these photos contain information that contributes to the identification of the assailant. They are also vivid and striking. However, when the assailant is identified - call him Bob - the photos can be discarded. They certainly need not occupy space on the investigator's wall when the important underlying information can be synthesized into a single sentence - Bob is the assailant.

Similarly, if I attend a festival and take a hundred photos, I may revisit them because they make me happy and because I seek to replicate the experiences in these photos. It helps to arrange them in some coherent order - from beginning to end - such that they tell a story and each photo is more meaningful. Perhaps I notice most of these photos have my friend Anne in them, and I realize that what really makes me happy is spending time with Anne and people like her. Given that storing and organizing these photos consumes space and time, I can reduce this narrative down to a single idea - I enjoy people with the characteristics and virtues of Anne. Likewise, I do not enjoy people like Bob. In both cases (leaving the metaphor), once the vital information is obtained, the fixations and the narrative they constitute become obsolete.

Narratives are useful for arranging discrete, emotive and vivid mental representations to produce insight into the nature of conscious experience and about what the future may have in store for us. However, the value of such expressive imagery diminishes once their underlying content is elucidated. Put differently, if the emotional underpinnings of fixations are provoking their vivid expression, a greater understanding of the content of fixations should quiet the emotional content and thereby diminish their vivid expression. ${ }^{14}$ When the vivid character of

\footnotetext{
${ }^{13}$ Indeed, the narrative appearance of the assemblage of images would increase if the viewer had a personal, emotionally charged relationship to the series of events (as opposed to a cool, objective investigator).

${ }^{14}$ This is an empirical claim, but simple introspection should show that a greater etiological understanding of an event seems to calm the emotional intensity associated with memory of the event, and thereby reduce the degree of
} 
fixations subsides, their informational content reduced to simple insights or maxims, the encompassing narrative need not persist. These perceptions then become emotively and sensibly neutral markers on someone's timeline and are useful for little more than temporal orientation. ${ }^{15}$

The ENT claims that it is a good thing to experience and conceive of one's life as a narrative, and that this is required for wellbeing (Strawson 2004, 428; Schechtman 2011). As discussed, proponents of the "strong view" argue that having an explicit, autobiographical account of one's life is necessary for their actions to have meaning, and for their episodes (experienced and anticipated) to cohere with each other across time (MacIntyre 1981;

Schechtman 2007). Mackenzie (2010) has compared not having a self-narrative to states of psychosis, where one is locked into a timeless space without any capacity to filter incoming sensory information (30-31, 39-40). Schechtman (2007) argues that it is beneficial to have stronger, personal affiliation (an empathetic connection) with events and potentialities in one's extended temporality. This would be, in-part, to prevent feelings of alienation to their lived experience, including obligations driven by their measurable histories (as discussed in footnote 1). While I will respond to these views in further detail throughout the remainder of this paper, it is important to note that such variations of the ENT encourage the preservation of self-narratives

vividity and overall intensity belonging to the memory's expression. Spinoza elaborates on this theme in Book 5 of his Ethics, for example in Postulation 3: "An affect which is a passion ceases to be a passion as soon as we form a clear and distinct idea of it."

${ }^{15}$ A criticism that may be raised against this position is that one loses something vital to their life-experience when they shed a rich, personalized narrative in favor of a neutral temporal metric. I will argue in Sections 4 and 5 that a life without the distraction of a narrative is actually more rewarding. It would be a topic for another paper to investigate the cultural contingency of narrativity. It seems consistent with a consumer culture that one would seek to commodify experience as memories, and construct a robust, important "self" with which they can compete in the marketplace. 
and thereby discourage the reflective and analytic processes I discussed in the preceding

paragraphs. In the following Section, I'll discuss how a persistent self-narrative could actually undermine one's sense of agency - a requirement for the good life.

\section{Critiquing Narrativity: How a Subject Connects to Charged Events}

\section{A. Daydreams: Experiencing Our Images As If They Were Percepts}

So far I have argued that narratives are composed of fixations, and that they are useful organizing devices but can be obstructive if allowed to persist. Strawson (2004) argues that even if episodics are more "located in the present" than diachronics (given that their present self does not relate to past or future episodes), they are not "more present in the present moment" (432). While I do not think that as a rule diachronics are less attuned to percepts and sensations (products of their immediate experience as opposed to imaginative reproductions), I think that contents of a narrative encourage the type of mental activity that is antithetical to present awareness (contra Strawson). I attribute this characteristic to the vivid expression and emotive character of fixations. These factors enable empathic access to, and diachronic identification with the first person perspective of these fixations. We are thereby motivated to revisit them and relive the events they represent - either as they were or as we would have liked them to be. Furthermore, their vivid character increases the likelihood that we will relate a present experience to these narrative chapters. In other words, we are primed to notice features of our present environment that relate to our fixations, at which point the associated fixation is brought to consciousness and our attention is bent back towards it (discussed further in 3.C). A fixation 
tempts revisitation - and it uses percepts to help us relocate it.

Important to note is that, although the fixation itself is something that manifests in the

present, its content is always either of the past or is of some potentiality. In the case of mental imagery, focusing our attention on the content of the image (which is to say the outer objects within the interior space of the image), allows for an experience of a memory or fantasy as if it were real. This is opposed to a type of awareness wherein we would fix the image in time and space and extrapolate from it, such that its "frame" (the empty space surrounding an image) becomes perceptible to us (McGinn 2004, 59-60). It would then be difficult to experience its content as percepts as opposed to imaginative representations. ${ }^{16}$ To become transfixed by the content of a fixation would be the antithesis of what is referred to as being "present." While this experience allows us to exercise a type of proxy agency, it detracts from our capacity to act with any meaningful impact outside the insulated arena of our imagination and memory.

In his book Mindsight (2004), Colin McGinn refers to this immersive tendency in his "fictional immersion theory," likening it to the same psychic reorientation that takes place while watching a particularly transfixing film (103-106). However, with the exception of psychotic delusion, he doubts that we very easily "believe" in our images (dreams) while awake. He does allow for daydreaming - especially in adolescents who show early early signs of mental illness as an avenue for so-called "dream belief.” Yet, McGinn doesn't seem to consider the importance

16 I emphasize "images" here, but I think the same psychic behavior takes place with thoughts (or linguistic representation). Here I would contrast the active thinking or narrating of a sequence, as in the playing-out of a conversation or a speech (rather than visualizing an action sequence internally, as with imagery), from arresting a line of thought, extrapolating from it, and studying it. The latter is akin to where we would see the "frame" of the image, except there may be no words to see rather than an arrested thought to replay and analyze. 
of existing attentionally within an image's spatial interiority (what Strawson calls a 'from the inside' perspective of a memory), versus extrapolating to perceive its frame $(2004,433)$. One reason for this exclusion could be McGinn's insistence that images are non-occlusive, meaning our experience of images is not blocked or interrupted by percepts. This assumption holds that, except in spaces of sensory deprivation, images (including daydreams) will already be exposed as artificial by their juxtaposition with percepts. Yet, as Nigel J.T. Thomas (2014) writes, this excludes the advent of "inattentional blindness," as well as the practical modifications of maladaptive daydreams (intentionally blocking out sense-input with dream-conducive music, for instance). The occlusive possibility of images implies that abstracting from an image such that its frame is exposed, is a vital quality for distinguishing images from percepts. When one goes deep within the interiority of a fixation, and percepts are sufficiently benign (such as being in an empty room versus at a carnival), I think dream belief is more likely.

That we are capable of experiencing the content of thoughts as if they were percepts (as immediate, organic, exogenous and structured sense data) I think is further demonstrated by our physiological response to the content of fixations. If I remember seeing a rabid dog barking at me in my backyard when I was a child, my palms sweat and my heart races as if the dog in my memory were present in its material form. That we can enter into the first-person perspective of our fixations as though it were a surrogate, and experience the content of fixations as if it were exogenous, allows us to exercise a type of proxy agency. Here we create the conditions in which we act, which is something we cannot do outside our narratives. Indeed, this is what makes these daydreaming activities so seductive (Bigelsen 2016, 569-571; MacIntyre 1981, 213). Yet, it 
renders the consequences of our actions within the dream insignificant, as the challenges we face are artificial. Furthermore, daydreaming can become automatic, addictive and disruptive to our everyday experience, as with the aptly named condition maladaptive daydreaming (Bigelsen 2016, 564).

I have argued that a persistent self-narrative encourages this type of psychic escapism and therefore diminishes our capacity to exercise genuine agency. Mindful reflection has shown to be an effective technique for reducing daydreaming tendencies (Harris 2014, 120). Indeed, activity in the area of the brain referred to as the default mode network (DMN) decreases during mindful exercises (as well as during psychological states of "Flow," which I will discuss in Section 4) (120-121). The DMN is most active during periods of self-representation and "mind-wandering" (which I take as synonymous with daydreaming), activities described by Brewer et al. as simply thinking about the past and the future (2011, 20256-20257). Despite Schechtman and Mackenzie's position that self-narratives are largely implicit, the simultaneous activity in DMN during daydreaming and self-representation suggest that self-narratives are often explicit. ${ }^{17}$ Narratives provide an insulated psychological environment devoid of valid opportunities for one to take action. I argue that reducing a narrative expands one's attentional capacity for the present, increasing their ability to act decisively and effectively.

\section{B. Imposing False Continuity}

Another disruptive tendency of persistent narratives regards what may be a reflexive effort to replicate the content of daydreams in our lived experience, i.e., as part of some narrative

\footnotetext{
${ }^{17}$ It's worth noting the narrative structure that is inherent to daydreams, as even MacIntyre (1981) addresses (211; Bigelsen et al. 2016). As stated, self-representation is taking place during daydreaming or 'mind-wandering,' (assuming one visits the past or future such that they connect to it diachronically). This suggests that self-representation takes place in a narrative format, and the process is carried out first-personally, actively, internally and explicitly (which is to say, as a daydream).
} 
quest (as with the "strong view" as Schechtman describes it)(2007). The issue implicit to such quests are twofold: A. The self that arrives at an objective could be changed from the self whose actions were originally directed towards the objective; B. The objective itself may escape possability (the context an event happened in may be impossible to reproduce, for example). In both cases, the effort to realize the content of a fixation (a person, place, title, experience, etc.) is incompatible with the ontological fact of flux (Graham 2015; Williams 2000, 45). Furthermore, the discontinuity of both experiencer and experience can be disguised by what Hume refers to as "custom."

David Hume's view on continuity casts doubt on the practicality of the extended telic quests, that are encouraged by (and supposedly made possible by) our self-narratives (MacIntyre, 1981). Hume argued that perceptual objects which frequently co-occur will be perceived as one, our attention moving across them so quickly that individuation is imperceptible (1.4.3.5). We thereby establish an idea of the parts as a single object: $01 .{ }^{18}$ After sufficiently repeated exposure to the conjoined parts, our attention will compulsively and habitually refer to $\mathrm{O} 1$ when presented with a resembling object (where only some of the components necessary to $\mathrm{O} 1$ are present). The transition between the present impression to the idea is so fast that we remain unconscious of the divide between the two $(1.3 .6 .3,1.4 .6 .7)$.

The effect of this process on our belief structure is similar to a film reel where two images (I'm referring to the percept and the idea) are transitioned between so quickly that they are seen as one. We, in effect, superimpose our image of $\mathrm{O} 1$ onto the present impression. We then filter the present object through O1 rather than recognizing its irregularities. McGinn (2004)

\footnotetext{
${ }^{18}$ In Hume's view on cognition, he posits that all mental artifacts are either impressions or ideas, the former being copied from the latter, and being generally less vivid or intense in expression (1.1.1.1,11). I use percepts as interchangeable with "impressions," and images as one instance of a Humean "idea."
} 
(drawing from Wittgenstein) describes this process as "Imaginative Seeing," where incoming sense data "elicits a memory image, which thereupon attaches itself to the percept of the moment" (50). This process, he explains, results in a "joint product" of exogenous sense data and mental imagery (2004, p. 48-50). McGinn cites instances where one sees a stranger S from afar and (often motivated by fear or desire) imposes a memory of acquaintance $A^{*}$ onto the basic structure of the stranger (this specific type of imaginative seeing is referred to as “seeing-as")(50). However, I think this process can be expanded to include when one does see $A^{*}$, or the object from which their mental image of $A^{*}$ was originally derived. The object (a human being) would have certainly changed by degrees, but the 'attachment of the memory onto the percept of the moment' obfuscates that change. ${ }^{19}$

Jesse Prinz (2002) defines "imagism" as thinking which consists of mental images that are "copied" from percepts (drawing from Hume). He notes the construction of categories or classes which are abstractions from particular images. For instance, we have qualifiers for a dog-concept that, when presented with those qualifiers (fur, tail, etc.) the concept is elicited, and the particular (dog) is subsumed under it with any disqualifiers (missing leg, purple fur, what-have-you) having been ignored or accepted as irrelevant (27-29). My view is that this process of subsumption works at an individual level as well. When presented with characteristics consistent (but not identical) with our concept of $A^{*}$, our concept of $A^{*}$ 's identity is triggered and we subsume the present percept under that identity-concept. Rather than create a new idea from the percept, we simply subsume it under the already established idea. This creates the illusion

\footnotetext{
${ }^{19}$ Aspects of the image would occlude irregular and incompatible aspects of the percept, or otherwise encourage a type of "inattentional blindness," where we do not consciously register the irregularities given the vivacity of the image/percept hybrid that is mostly symmetrical. Anxiety in the subject is likely to increase as symmetricality decreases and antagonism between the two kinds of phenomena increase.
} 
that this idea accurately represents the object we are presented with. ${ }^{20}$ We come to regard our $A^{*}$-image as representative of a continuous, unified entity. Hume calls the strength of association between parts of a perceived object - such that we attentionally refer to $A^{*}$-image from being presented with some of its parts - “custom.” He calls the subsequent, compulsive attribution of identity to an object an act of "habit", (1.3.7.4, 1.3.8.14).

Hume explains that one can reflect and discover the error the mind makes in attributing continuity to changing objects, yet it is impossible to override it for long. Rather than persisting in a chaotic flux of perceptions or constantly expanding our categories of objects given slight differentiation, we explain contradictions as "accidents" in either perception or material (1.4.3.7). We then invent the notion of an underlying substance upon which these accidents happen. The underlying substance we invent for our fluctuating identity is actually the self (1.4.6.6). The objects of intentionality, with which a subject identifies, undergo change that is usually subtle enough to be explained away as mere modifications to an otherwise continuous assemblage $(1.4 .6 .8,14)$. For example, John's abstract self-concept (or category) of being a father will continuously subsume the present conditions of his identity (his assemblage of memories, projections, ideas around having a family) established however long ago he had kids. Subtle irregularities, such as his children growing and requiring differing fatherly duties, will be overridden or integrated into his overarching self concept. The similar process of imaginative seeing takes place with his physical characteristics. John has an image in his mind of what he

\footnotetext{
${ }^{20}$ The subsumption under categories that Prinz describes is probably responsible for the false continuity that pertains to concepts rather than images, as in the continuity of one's self-concept or the idea of a perfect career or marriage. Imaginative seeing would be more responsible for the false continuity imposed onto the appearance of a person, a place of work, etc.

${ }^{21}$ Contemporary psychological explanations for our ascribing continuity where there is none, may involve the economizing of glucose in the brain (Kahneman 2011, 43). It simply saves energy to infer a whole from some of its parts, to attribute sameness to resemblance, rather than constantly constructing new concepts.
} 
looks like and he can impose this image on the new person he meets in the mirror every morning (a new wrinkle, gray hair, etc.) In both cases, barring some serious disfigurement or the tragic loss of his children, John will continuously reproduce a fictitious continuity for himself. ${ }^{22}$

The notion of a narrative quest assumes that it is the same self who realizes the extended telic objective, and that the object of interest is realizable as one remembers or imagines it. Yet, the advent of imaginative seeing and category subsumption illustrate how we mistake resemblance for sameness out of habit. This tendency could undermine the practicality of long-term, telic endeavors which assume and require constancy. Referring to the earlier analogy, I may encounter "Bob" two decades after he committed his crime, at which point he could have had brain surgery on his amygdala and undergone a fundamental transformation in identity.

Yet, my memory of Bob as a violent offender could easily override any suggestion of this transformation. If the present "Bob" is similar enough to cue my memory, and my memory of Bob is sufficiently vivid and emotively charged to be readily cued, my attention will be referred automatically from the present "Bob" to my established idea of Bob. As described above, I will thereby subsume this new person under a pre-existing idea rather than developing a new idea having taken present irregularities into account. Hume's view on continuity poses problems for narratives which, in this case, have the theme of retributive justice (the "strong view" of narrativity indeed tends to be thematic)(Schechtman 2007).

Likewise, I may go through a variety of telic activities to meet Anne, but fail to recognize that she has also undergone a radical change in personality. Given our habit of mistaking resemblance as sameness, I may superimpose my idea of who Anne is onto this truly different

\footnotetext{
22 The phenomenon of imposing false continuity is also described in terms of mental models of an expected world, such as by Charles Perrow in Normal Accidents (1999) where he writes we "process the information that fits our expected world and ... exclude the information that might contradict it" (214).
} 
other. I may also be less aware of subtle changes in my own expectations and desires (i.e. my self), if they are incompatible with my established idea of who I am and what I want. The change individuals undergo which we may nevertheless remain unaware of, undermine the practicality of narrative quests that in this case have a romantic theme. However, studying the constituents of our narrative objectively and detachedly (as is practiced during meditation) could yield insights into their more subtle and complex content (Kornfield 1979, 44; Santorelli 1992, 280-281, 306-307). If we examined our narrative segment of the festival (from the analogy Section 2), we could discover some of the virtues we value in others. We could then consolidate this information to develop a conception of our ideal person that stands independent of any specific fixation. Cultivating relationships along an informed set of criteria is more practical than the telic pursuits of narrativist romantics. ${ }^{23}$

Schechtman (2007) argues that the experienced past and anticipated future condition the present. To some extent this is unavoidable, as in having been hungry for hours makes a meal taste better. However, the extended temporality by which we measure our food intake and explain growing hunger and irritability is too simple to qualify as a narrative (as discussed in Section 2). Narratives are composed of charged events, and it is these events which condition the present in anyway that is non-trivial. The present is conditioned in that we are attracted to or repelled by present experiences based on their resemblance with the fixations of our narrative. As stated, we are prone to make mistakes regarding the continuing identity of objects that inhabit our narrative, including the idea we have of our self that moves across a narrative. This error restricts our ability to perceive and understand the present and act effectively, rationally and

\footnotetext{
${ }^{23}$ Psychiatrist Stephen Grosz offers a detailed illustration of the folly of romantic narratives in The Examined life (2013, 109-117)
} 
otherwise optimally. ${ }^{24}$ It furthermore carries a debt, whereby individuals must eventually reconcile their narrative selves with their constantly changing environment. ${ }^{25}$ I will expand on this point further in Section 4, which regards how we might act and perceive without a narrative.

\section{Irrational Narrativity: Biases, Heuristics and Priming}

Proponents of the ENT praise self-narratives for their capacity to enable teleological quests and deem them as necessary for making plans (as discussed in Section 1, and critiqued in the previous Section 3.B). The final criticism I would raise against this aspect of narrativity is that the types of goals which are constituted by charged events encourage irrational and often controlling behavior (as one's range of acceptable outcomes is restricted to the realization of fixed narrative episodes). Charged events carry an emotive gravity and have an empathic potential for us as we are now. If the fixation is positive, we strictly seek to replicate these moments in the present. If they are negative we avoid them. Therefore, one's perceptual range is limited in that they become primed to notice sense objects that are consistent with their narrative.

Having a broader range of perceptual awareness allows one to register myriad opportunities and possibilities. Diminished narrativity enables one to recall information in terms of relevancy as opposed to saliency, reducing the strength of various biases and heuristics on our decision making. Consider a professional runner that fails to prepare for a race given an overconfidence bias having one the previous race. Retaining the charged quality of the memory

\footnotetext{
${ }^{24}$ The experience wherein individuals strive towards a much desired ends and then are mystified by their dissatisfaction (or unlasting satisfaction) with this ends, is common enough that I am not sure it warrants further examples. To give just one, the discorrelation between expected and experienced happiness in marriage (referred to as an 'error in affective forecasting,') could in part be explained by this issue with discontinuity at the heart of telic quests. (Kahneman, 2011, 398-399).

${ }^{25}$ It would be worthwhile to study empirically whether aging is more emotionally and psychologically challenging for diachronics vs episodics. My assumption would be diachronics have a more visceral sense of being pulled apart by time, whereas episodics are more "happy-go-lucky" (as Strawson puts it)(2004).
} 
of winning, through reliving it as a daydream and positioning it in a broader narrative of success, discourages a thorough introspection of the event. ${ }^{26}$ The runner fails to recognize that ease in winning the previous race is reducible to the race having taken place in his home town and to his close competitor having an injury. He therefore fails to practice sufficiently and loses the second race. Similarly, an athlete may compete beyond their prime, training obsessively and risking injury because of a desire to replicate positive episodes of their narrative independent of changing conditions. A narrative coded with episodes of celebrity would encourage an overconfidence bias as well as confirmation bias, as in listening to fans who encourage continued competition over trusted coaches and family members.

Narratives similarly increase the prevalence of heuristics. A fixation that is particularly idiosyncratic and fear-provoking but statistically insignificant, like an act of political terrorism in the United States, could provoke certain phobias associated with public places or garner support for legislative action that increases police presence and surveillance. Decoding fixations (through mediation or therapy), and understanding the etiological idiosyncrasies of an event, reduces (in this case) the strength of both availability and affect heuristics (Kahneman 2011, 138-140). ${ }^{27}$

\section{Telic vs Autotelic Behavior}

\footnotetext{
${ }^{26}$ Neuroscience may show that narratives allow for faster connectivity between memories, so that a related memory could gain charge from another memory that is presently being revived. Perhaps narratives enhance the neurological connections made between memories, but is this universally beneficial?

${ }^{27}$ There are further problems posed by the narrative format which could be the subject of other papers, and I will list three. The first regards the negative tendency of our autobiographical memories, as described in R.F. Baumeister (2001) in his essay "Bad is Stronger than Good." The second regards Mackenzie's (2011) claim that we become "concretely individuated" through our self-narratives, and research demonstrating that experienced hyper-individuation may be associated with negative affect and mental illness (Hidaka, 2012). The third regards the long-term consequences of telic striving. Insofar as our actions are telic, the value of our own work and our lived experience is threatened by change that would make the realization of some telos undesirable or impractical. Kieran Setiya (2014) outlines a similar issue in his discussion on midlife crises, arguing that telic actions bring about a kind of malaise when one realizes that they will not live long enough to accomplish many of their long-standing goals. Paradoxically, in accomplishing one's efforts, they are also removing some rewarding project from their life. His solution to both issues is a reorientation towards "a'telic" or autotelic activities, which I will discuss throughout the remainder of the paper.
} 
Thus far I have offered a selection of criticisms that could be raised against the ENT.

Narrative theorists may argue that, despite these objections, a self-narrative is still our best option for living agentally. Without it, we would be trapped in a state of disorientation where our actions and lives are nonsensical to ourselves and others (Mackenzie \& Poltera 2010). I will now shift my focus towards a positive account of non-narrative selves and explain how they qualify as agents, in response to this line of reasoning.

It is the topic of another paper to fully discuss variations on agency are autotelic, as the standard conception of agency holds action to be defined by explicit intentions towards an ends (Schlosser 2015). For my purposes in this paper, I will assume a definition that is somewhat minimalistic, allowing for an agent to act intuitively and reflexively, guided perhaps by tacit norms or maxims rather than explicit intentions (Barandiaran et al., 2009). Agency, as Mackenzie (2010) defines it, is most basically the capacity to reflect, deliberate, choose, act and respond to reasons. I recognize agency as a necessity if one is to lead a quality existence, and as a qualification for autonomy and a personal sense of freedom, efficacy and empowerment. Taking action that, if not explicitly intentional, is the product of sustained reflection, self-knowledge and reasoned deliberation, is itself inherently rewarding. ${ }^{28}$ Exercising agency in this regard builds the confidence necessary for taking on further challenges, for taking risks with the assurance of one's capacity to rebound after failure. It is therefore requisite for personal development and for one to achieve autonomy from those who may otherwise exploit their lack of confidence. Agency is vital for one's well-being and for the capacity to live well, regardless of

\footnotetext{
${ }^{28}$ In this sense I agree, for the most part, with Machiavelli's (1514) famous line (taken from Giovanni Boccaccio), "It is better to act and repent than to not act and regret."
} 
what an individual determines a good life to be. Such action needn't be willed towards a telos, however, as autotelic practices may show to be more rewarding than the alternative.

Mackenzie (2010) argues that a self-narrative is constructed as an initial exercise of agency, and agency then depends on the survival of the narrative (33-34). In contrast, I have offered instances when agency is undermined by narrativity. Self-narratives cause one to be more distracted, as when one escapes into their narratives through daydreaming or regularly defers attentionally to an 'image of a telos' or some other aspect of their narrative that is triggered by sense perception (MacIntyre 1981, 215-216). There is a further tendency to superimpose aspects of one's narrative onto their sense perception through "imaginative seeing." Therefore, when a narrative decomposes (one having decoded and consolidated its informational content), one's attention is available to register a wider spectrum of incoming sense data, and for a longer duration. One whose attention is sustained upon the present has easier access to autotelic "flow states," the rewards from which are not contingent on a future outcome but are inherent to the activity. Flow states describe practices where one's attention is sustained within the activity they are undertaking. One thereby loses a sense of time (as in the temporal extension of a narrative) and a sense of self (Nakamura \& Csikszentmihalyi 2009, 91).

Defining characteristics of flow include increased positive affect, full employment of one's capabilities and the loss of reflective self-consciousness (Nakamura \& Csikszentmihalyi 2009, 90). An example would be when a player is moving a soccer ball towards a goal and their attention is entirely invested in the moving of the ball with their foot. In this case, even the literal goal is proximal and contingent on the moment, as in it is malleable to changes happening actively and presently (making the winning-goal may quickly become impractical). The 
immediate sensation of kicking the ball is the sole recipient of one's attention. Perception (of passing opponents, the feeling of the ball against the clete, changes in the wind, etc.), recall of the relevant memory, adaptation of memory as action, perceived feedback, recalibration and further action - are together part of a seamless phenomenal exchange. The thought of one's self as an actor or thoughts of a fixed, extended telos do not enter into the sequence at all (Nakamura \& Csikszentmihalyi 2009). ${ }^{29}$

This description of flow states contradicts the claim made by MacIntyre (1981), that there is no experience of the present without attentional reference to an abstract telos (215). The intervals in which one's attention is entirely absorbed in their activity may be brief, but they do happen and they can be expanded with effort. They are easier, or perhaps only possible if the action itself is initially autotelic. To achieve a state of flow, one cannot alternate their attention between the action at hand and an abstract objective on which the value of their present action depends. The long-term goal (if there is one), can change and vanish, as it is simply a means to temporal orientation or perhaps a source of initial motivation. The reward, though, is inherent to the activity, and therefore one's attention is more easily dedicated to that activity (Nakamura \& Csikszentmihalyi 2009). I argue that the attentional subject could then qualify as a minimal, experiential self, yet one that is still capable of acting effectively from the relevant synthetic maxims (maxims produced from reflection upon a narrative, as discussed in Section 3)(Zahavi 2007)..$^{30}$

\footnotetext{
${ }^{29}$ Daniel Kahneman's popularized "system 1" of automatic thought may be at work here, though I would argue one can contemplate actively and detachedly (system 2) and still be in a state similar to flow. Such thinking would contrast with daydreaming and not necessitate a self-narrative (Kahneman 2011, 105).

${ }^{30}$ I will elaborate on this view of the self, and provide a final comment on selfhood in Section 6.
} 
The notion of autotelism deserves further unpacking, here, as it is relevant to the types of actions I feel are more likely to be undertaken by non-narrative selves. MacIntyre's claim that all intelligible actions have ends (or the standard conception of agency which holds all actions have explicit intent), seems more plausible if a "telos" could be reduced to those of the preceding examples: kicking a ball to move it, because one "feels like it" or because it brings them joy. To maximize one's capacity to act optimally (as in, to effectively bring about positive affect), I argue that goals would best be malleable, proximal, largely subconscious and themselves a means to the process. Two friends may use a score sheet as a means to encourage competitive, engaging play, though the scores are insignificant. Likewise, someone could set an arbitrary destination for their walk, for orientation or motivation. The real objective, however, is the walk itself. This differs from having a fixed destination - for instance, a court appointment that one is late for, which (as a thought) occupies much of one's attention.

It is not that one must be completely indifferent towards an end result. In the example of the autotelic walk, it is certainly more likely that one chooses the arbitrary destination of getting ice cream rather than going to the morgue. However, the end result is not the purpose of the action, rather reward and motivation emerges from the action itself. Regarding what they call “emergent motivation,” Nakamura \& Csikszentmihalyi (2009) write that during a state of flow, "what happens at any moment is responsive to what happened immediately before within the interaction, rather than being dictated by a preexisting intentional structure located within either the person... or the environment" (91, italics added). Such action differs characteristically from one's having a fixed goal to which all their effort is directed and on which one's happiness is contingent. As discussed in Section 3.C, objectives on which one's self-worth, and the value of 
individual actions are contingent, are constituted by charged events. They are attempts to replicate positive episodes of one's narrative (or avoid negative episodes), based on a superficial resemblance. Given their tendency towards futility (per Section 3.B,) despite their persistent veridicality (per Section 3.A,) the pursuit of such ends is more likely to be aggressive and destructive.

A final point in support of autotelic activity for overall wellbeing: during telic action the capacity one has to appreciate and enjoy is more likely to be outsourced to an abstract telos. This enjoyment one enacts in a daydream or waits to experience when the telos has been realized. When one commits their attention to their task completely, without great regard for ends, this capacity to appreciate can only be expended in the present. This, I argue, leads to more enjoyable activities, even those as commonplace as taking a walk or washing dishes. As I will describe below, I think autotelic activities are more easily undertaken with an episodic temporal orientation.

\section{Episodic Selfhood}

Theorists such as Mackenzie (2010) may argue that because narratives operate as "implicit organizing structures," a narrative is still at work during flow states. However, an important distinction (as I began discussing in Section 2) must be made between a subject's working temporal schema and an elaborate life-story. The capacity to orient oneself spatially and temporally, and to recognize the direction towards which they are going seems unavoidable and unspecific to humans (Zahavi 2007). As Zahavi (2007) and others have argued, a basic temporal ordering is far too inclusive a concept of narrativity for it to transcend triviality (196; Schechtman 2013, 408-411). 
MacIntyre (1981) seems to overlook this distinction, regarding the order imposed by a cookbook as comparable to a narrative in that each step derives its meaning from its placement in a larger sequence (the recipe), and the context within which it exists (meal preparation)(209). Similarly, Mackenzie (2010) presents an all-or-nothing view of narrativity, arguing that without it one is lodged in the "stagnant present" and forsaken of any filter to organize sensory data (32, 39-40). Both invoke a dichotomy where one engages in narrativity or is left with a shattered temporal orientation. I argue that the type of temporal ordering of a cookbook or assembly manual is not comparable to a literary-styled self-narrative (no one would confuse the Toyota Camry Owner's Manual with The Lord of the Rings), though the impersonal temporal extension akin to the former is perfectly conducive to agential living (Dennett 1992).

Nakamura \& Csikszentmihalyi (2009) have posited that "autotelic personalities," who report more frequent flow states, tend to have clearer long-term goals (99). Yet, they also argue that the goals of autotelic action are recognized as a "means to the process," (though it is not entirely clear if this applies to long-term objectives). It is clear, however, that autotelic individuals operate with a working temporal schema. Yet, contra MacIntyre (1981) the value of an action by which one enters into a flow state is derived through the practice itself (Nakamura \& Csikszentmihalyi 2009, 89). If asked why one gardens, the answer may not be to please one's wife or to prepare for winter (to use MacIntyre's example) - though these may be potentialities inhabiting their temporal extension $(1981,206)$. The answer could be, "I garden to garden," or "I garden because I like to." I see this as a satisfactory answer that renders the action both intelligible and valuable. 
Fixations function as the peaks and valleys of one's otherwise one-dimensional temporal schema. This is to say, such a schema is shaped or distorted by these relatively intense highs and lows, into something that resembles a story. ${ }^{31}$ Memories can operate as markers to symbolize the passage of time, but it is compact and charged memories and fantasies that command the landscape of one's temporal extension, determining from where one appears to be coming and to where they appear to be going. Caveats which I think could reasonably be placed on one's temporal schema, such that it does not qualify as a narrative, include that the schema should vanish when orientation is complete so that one can return attentionally to their practice. Furthermore, long-term objectives should be malleable to the immediate feedback from the action, and their realization (publishing a book, finishing a painting) should be less important than the practice that lead to or followed from it. One should also be able to jettison a long-term objective if circumstances change, change which they would be more attuned to having been relieved of a distracting narrative. One should feel less resistance to changing long-term plans given that the value of a series of actions is not contingent on the realization of some potentiality - some fixed telos. Rather, the value is redeemed consistently through their performance. ${ }^{32}$

\footnotetext{
${ }^{31}$ This may happen intentionally, as discussed in Section 2 where one systematizes vivid memories like photographs for better organization. It may also happen organically, automatically and necessarily, as simply inheriting "charged events" generates a narrative, for a narrative is the form that one's phenomenal experience (as in recollection or projection) of such an event takes (Schechtman 2007).

${ }^{32}$ A criticism that could be raised against these types of goals, is that charged, telic objectives to which we have a diachronic connection and on which much depends (financial reward, career advancement, even survival, etc.) are the most motivating, and therefore the most likely to inculcate a flow state. Further research may be needed to verify if this happens, and to verify if such slow states are emotionally comparable to those I have described. Regardless, I would maintain that such telic quests are subject to the same upsets associated with discontinuity and daydreaming that I discussed in Section 3. Even if the flow state was more easily entered into, it would be more easily interrupted by the 'image of a telos,' upon which the value of one's present actions largely depends (I note the precarious nature of this value contingency in footnote 17). Insofar as one is able, I would say practicing autotelic activities offer more stable, consistent benefit to one's well being and one's sense of agency (for reasons discussed in Section 3 - 5).
} 
An episodic self, as Strawson (2004) defines it, is one who does not sense that they have a narrative or that their self persists across time. They may have a temporal schema that consists of memories and potentialities, but there is no sentimental attachment to the self inhabiting that temporal extension, and there is no intimation that their self exists anywhere and at anytime but presently (430-433). I understand this claim to mean that a subject does not inhabit their fixations through the first-person perspective afforded to them by their fixations. One is then not given to (erroneously) experience the objects of their representations as perceptual (rather than imaginary) objects $(2007,171)$. "Dream belief," in this regard, may encourage the sense that it was me in my memory, as I am now, or (in the case of fantasies) as I am going to be. Another way of phrasing this distinction is to say that a diachronic self continues or builds upon their memories (or the story composed of those memories), but an episodic self inherits those memories from a truly different self.

To explain this further, I can remember my third-grade classroom objectively (from an impersonal third-person vantage point whereby the frame of the memory - and the empty space beyond it - is exposed) or I can live out the memory subjectively, experiencing it either from a first-person or from a third-person point of view (wherein I can view the class as a "fly-on-the-wall" within the classroom as opposed to abstracting from the memory altogether). ${ }^{33}$ The latter produces the sense that it was the twenty-six year old me in the memory, and not the eight year old me. I can do this likewise with fantasies or potentialities, imagining my one year present-day old nephew's high school graduation as if it was twenty-six year old me at the ceremony, not the hypothetical forty-three year old me. It may be impossible to actually

\footnotetext{
${ }^{33}$ The functionality of this process was explained in Section 3.A
} 
experience the past as we experienced it when it was happening. We can experience it

objectively or through the first personal lense, but always as the subject that we currently are.

The latter gives us the sense that there has been, and will be, one self persisting across time.

Strawson (1999) argues that it is a metaphysical fact that selves do not last more than a few seconds (Schechtman 2007, 174). My point of view is that any indulgence notions of self-continuity must ultimately reconcile with an ontology that is in a constant state of flux. ${ }^{34} \mathrm{On}$ the other hand, objective, depersonalized consideration of our past and our future encourages an episodic temporal disposition. Reflection upon salient memories and ideas diminishes their vividity, thereby diminishing the narrative structure which they would come to constitute, allowing one to become episodic. Without a collection of fixations with which we identify personally, we are less apt to revisit and relive the past through daydreams, or attempt to replicate parts of our narrative presently. Our attention is then available to focus on the present (on a wider spectrum of incoming sensory information), enabling the fullest employment of our capabilities - the apotheosis of agency. As I have argued previously, it is agency - the capacity to act effectively from reason and reflection, that is necessary to live well.

\section{What is a 'self'?}

In this paper, I have discussed various views of the self - that it is an abstractum, a theoretical byproduct of narrative overlap, metaphorically akin to a rubber-band ball (Dennett,

\footnotetext{
${ }^{34}$ A possible criticism against this episodic orientation is that it negates social responsibility for future or past actions. However, one can be responsible for a future self even if it is not strictly speaking 'their' self, especially if their present actions largely determine who that self becomes. This is true in the case of raising children, for instance, where a parent still holds some responsibility if a child they neglected grows up to be antisocial and dangerous. One may, however, be resolved of responsibility for past actions if they can demonstrate relevant and sufficient change (as in, having brain surgery that removes a tumor which was causing one to act unusually violent). I would also note that one may be more emotionally responsive to long-term social issues (such as climate change) if they are attentionally available, as is made possible with an episodic temporal orientation. The lack of egocentrism which I suspect comes with diminished narrativity, I think could also enhance social responsibility.
} 
1991); That it is synonymous with a narrative (MacIntyre, 1981); That it exists in a series of gradations (Zahavi, 2007); That it can alter between being diachronic or episodic (Strawson, 2004). The view I find most compelling draws from Hume and Zahavi. I agree with Hume that the strong association between perceptions, the compulsion to refer from one to the next out of habit, gives us some sense that there is a force that is binding them together. I think that we have an idea of who we are in some specific capacity (who I am as a student, son, friend, etc.) and, as with any object, it is tempting to subsume a present experience under that established idea, ignoring irregularities and ascribing continuity. Our compulsion to do this also appears to come from some force - a self or a soul, but I think it is still attributable to habit (as noted in Section 2).

Strawson (2011) argues that Hume allows for the type of minimal self that Zahavi (2007) discusses, as there must be an experiencer who experiences the flow of perceptions. This experiencer may not qualify as the 'force' which unites perceptions - that unity can still be attributed to habit (though if and how habit exists as a property of this experiencer, I do not know). Yet, it is still an integral part of the subjective consciousness. Antonio Damasio refers to this locus of subjectivity as "core consciousness," from which a "core self" emerges, a self that is distinct from the "autobiographical self" of "extended consciousness" (Zahavi 2007, 185-186). My view is that when one undertakes the type of focused, mindful reflection discussed in Section 3, or when one experiences a flow state, they inhabit this core self. Indeed, it is from these states that we see less activation in the DMN, where autobiographical narration takes place (Harris 2013; Brewer et al. 2011).

However, it is not as if the structure of the autobiographical self is destroyed when one enters into these core-self states. From a state of minimal selfhood, constituted by pure 
awareness, one is capable of viewing their own narrative objectively. By objectively, I mean one does not inhabit their narrative first personally (or even third-personally, such that they occupy the interiority of an image as a "fly on the wall"). If the segment of narration being apprehended is purely linguistic (as in "I moved here from California to start a family," as opposed to an imagistic representation of this episode), it is fixed, abstracted from and revisited. The concepts and events being described are studied detachedly and equanimously. If emotions arise, those can also be abstracted from and examined equanimously. It is during this state that one can gain etiological insight about their life's history. ${ }^{35}$ These insights are achieved when one introspects a fixation objectively, rather than inhabiting an episode's subjective lense (as discussed in Sections 2 and 5). Analogously, the person with the best understanding of the ongoings on an airport tarmac is not the pilot or any of the passengers, but the person watching from the air-traffic control tower.

My view is not that one should reside in the tower forever - indeed this is probably impossible. Yet, taking an objective perspective of one's life, from the vantage of core-self, allows one to process and interpret one's narrative and the emotions which animate and illuminate it. One can then return to a more complex self-state wherein they inhabit a working temporal schema, but not to the extent where they habitually refer to their self as the protagonist of a narrative quest. This sort of narrative identification yields futility and frustration (as discussed in Section 3.B and 3.C).

\section{Conclusion}

In this paper I have critiqued narrative views of the self, arguing that self-narratives are

\footnotetext{
${ }^{35}$ Such exercises are descriptive of meditation (Harris 2016; Kornfield 1979; Santorelli 1992; Hanh 2007), as well as Stephen Kosslyn's (1994) empirical studies on introspection and image inspection (327-344).
} 
largely composed of charged events to which we connect diachronically (Strawson 2004;

Schechtman 2007). The systematization of these fixations into a life story contrasts with the impersonal temporal schema of the episodic self. Yet, an episodic schema is perfectly sufficient for orientation and navigation. A narrative may be a useful intermediary organizing device for particularly emotive episodes, but an optimal self-experience is minimal. Having a persistent self-narrative prevents us from being attentionally present. This results from our tendency to relive the episodes of our life story, and to pursue the realization our episodes via extended teleological endeavors. I have argued that the good life is not achieved through narrativity, but through informed, autotelic action. 
Bibliography

Bigelsen, Jayne; Lehrfeld, Jonathan M.; Jopp, Daniela S.; Somer, Eli

Maladaptive daydreaming: Evidence for an under-researched mental health disorder, Consciousness and Cognition, Volume 42, 2016, Pages 254-266, ISSN 1053-8100, https://doi.org/10.1016/j.concog.2016.03.017.

Brewer, Judson A., \& Worhunsky, Patrick D., \& Gray, Jeremy R., \& Yi-YuanTang, Weber, Jochen, Kober, Hedy. (2011). Meditation experience is associated with differences in default mode network activity and connectivity. Proceedings of the National Academy of Sciences, 108 (50) 20254-20259; DOI: 10.1073/pnas.1112029108

Dennett, Daniel C. (1992) The Self as a Center of Narrative Gravity. In: F. Kessel, P. Cole and D.

Johnson (eds.) Self and Consciousness: Multiple Perspectives. Hillsdale, NJ: Erlbaum Danish translation, "Selvet som fortællingens tyngdepunkt," Philosophia 15 275-88, 1986.

Graham, Daniel W., "Heraclitus", The Stanford Encyclopedia of Philosophy (Fall 2015 Edition), Edward N. Zalta (ed.), URL = $<$ https://plato.stanford.edu/archives/fall2015/entries/heraclitus/>.

Gronsz, Stephen. The Examined Life. New York, W.W. Norton \& Company, 2013, pp. 109-17. Hanh, Thich Naht. The Art of Power. 2007. Harper Collins. New York, NY. Ch. 1, 3, 9

Harris, Sam. Waking Up. 2013. Simon \& Schuster Paperbacks. New York, NY.

Hidaka, Brandon H. "Depression as a disease of modernity: explanations for increasing prevalence." Journal of Affective Disorders, vol. 140, no. 3, 2012, pp. 205-14. 
Hirst, William, and Elizabeth A. Phelps. "Flashbulb Memories." Current Directions in Psychological Science 25, no. 1 (2016): 36-41.

Hume, David. A Treatise of Human Nature, 1738. Barnes and Noble Inc, New York, NY. 2005.

Kahneman, D. (2011). Thinking Fast and Slow. New York City, NY: Farrar, Straus and Giroux.

Kosslyn, Stephen M. Image and Brain. Cambridge, MA: MIT Press, 1994.

Kornfield, Jack. "Intensive Insight Meditation: A Phenomenological Study." Journal of Transpersonal Psychology 11, no. 1 (1979).

Korsgaard, Christine M. Self-Constitution: Agency, Identity and Integrity. Oxford: Oxford University Press, 2009.

Mackenzie, C. (2014). Embodied agents, narrative selves. Philosophical Explorations, 17(2), 154-171.

Mackenzie, C., \& Poltera, J. (2010). Narrative Integration, Fragmented Selves, and Autonomy. Hypatia, 25(1), 31-54.

Mackenzie, Catriona (2009). Personal Identity, Narrative Integration, and Embodiment. In Sue Campbell, Letitia Meynell \& Susan Sherwin (eds.), Embodiment and Agency. Pennsylvania State University Press. pp. 100-125.

MacIntyre, Alasdair. After Virtue. 3rd ed. N.p.: University of Notre Dame Press, 1981.

McGinn, C. (2004). Mindsight: Image, Dream, Meaning. Cambridge, MA: Harvard University Press.

Nakamura, J., \& Csikszentmihalyi, M. (2009). The concept of flow. In Snyder, C. R., \& Lopez, 
S. J. (Ed). Oxford handbook of positive psychology. Oxford University Press, USA, 89 105

Perrow, C. (1999). Normal Accidents: Living With High Risk Technologies (p. 214). N.p.: Princeton University Press.

Prinz, J. Furnishing the Mind: Concepts and their Perceptual Basis. Boston, MA: The MIT Press, 2002.

Santorelli, S. F. (1992). A qualitative case analysis of mindfulness meditation training in an outpatient stress reduction clinic and its implications for the development of self-knowledge (Order No. 9233158). Available from ProQuest Dissertations \& Theses Global. (304022127).

Schechtman, M. (2001). Empathic Access: The Missing Ingredient in Personal Identity. Philosophical Explorations, 2, 95-111.

Schechtman, M. (2007). Stories, Lives, and Basic Survival: A Refinement and Defense of the Narrative View. Royal Institute of Philosophy Supplement, 60, 155-178. doi:10.1017/S1358246100009656

Schechtman, Marya. "The Narrative Self." In The Oxford Guide to the Self, edited by Shaun Gallagher, 396-416. Oxford: Oxford University Press, 2011.

Setiya, Kieran. "The Midlife Crisis." Philosophers Imprint 14, no. 31 (November 2014). Gallagher, 396-416. Oxford: Oxford University Press, 2011.

Spinoza, B. (1994). The Ethics (E. Curley, Trans.). In E. Curley (Ed.), The Ethics and Other Works. Princeton, NJ: Princeton University Press.

Strawson, G. (1999). The Self and the SESMET. Journal of Conscious Studies, 6(4), 99-135. 
Strawson, G. (2004). Against Narrativity. Ratio, 17(4), 428-452.

Strawson, Galen. The Evident Connexion: Hume on Personal Identity. Oxford: Oxford University Press, 2011.

Thomas, N. (2014, March 18). The Multidimensional Spectrum of Imagination: Images, Dreams, Hallucinations, and Active, Imaginative Perception. Humanities, 3, 132-184.

Williams, Paul. Buddhist Thought. 2000. Routledge. New York, NY. pp. 21, 43-58.

Velleman, J. David. "Well-Being and Time." Pacific Philosophical Quarterly 77 (March 1991): 48-77.

Zahavi, D. (2007). Self and Other: The Limits of Narrative Understanding. Royal Institute of Philosophy Supplement, 60, 179-202. doi:10.1017/S1358246107000094 